\title{
TRENTO Y EL MARCO INSTITUCIONAL DE LAS ÓRDENES RELIGIOSAS FEMENINAS EN LA EDAD MODERNA
}

\author{
POR
}

\author{
CARMEN Soriano Triguero \\ Universidad Complutense
}

\begin{abstract}
RESUMEN
E1 Concilio de Trento establece una reforma general de la organización de la Iglesia Católica, que afecta de una manera especial a los conventos religiosos femeninos. Estos cambios depararon una evolución dentro de estos cenobios. La autora estudia su influencia en las diferentes órdenes religiosas.
\end{abstract}

\section{ABSTRACT}

The Council of Trento establishes a general Reform of the organization of the Catholic Church, that affects especially to the feminine religious convents. These changes where making an evolution within these monasteries. The author studies its influence in the different religious orders.

\section{LOS DECRETOS TRIDENTINOS PARA LAS RELIGIOSAS ¿UNA NUEVA REFORMA?}

Durante mucho tiempo la historiografia sobre la Iglesia española en general y sobre las órdenes religiosas en particular ha venido insistiendo en la importancia del Concilio de Trento dentro del marco general de reforma disciplinaria del clero en el siglo XVI. Para las componentes femeninas en concreto, los decretos tridentinos supusieron la institucionalización de un único modelo ortodoxo de vida religiosa, la clausura contemplativa. Al contrario de lo que ocurrió

Actas del I Congreso de Historia de la Iglesia y el Mundo Hispánico

Hispania Sacra, 52 (2000) 
en otros Estados europeos, sobre todo en Francia y los Países Bajos, en España la mujer quedó supeditada a un segundo plano en la Iglesia católica, relegada a una vida pasiva con unos fines exclusivamente sobrenaturales: rezar por el resto de la humanidad'.

Pero iconstituyeron los decretos tridentinos una verdadera revolución? A la luz de la oposición levantada en algunos claustros y los problemas surgidos en otros muchos podriamos dar una respuesta afirmativa, pero lo cierto es que España contaba con una tradición reformista propia que tuvo mucho éxito en la Corona de Castilla y en ciertas órdenes religiosas: nos referimos a la ejecutada por los Reyes Católicos y el Cardenal Cisneros a finales del siglo $\mathrm{XV}^{2}$. La reforma cisneriana insistió en los mismos contenidos que después van a desarrollar los padres conciliares: la clausura, los votos, la observancia de la regla, el estado material de las religiosas y la incorporación completa al aparato oficial de las órdenes masculinas. En una política de apoyo absoluto a los movimientos reformistas surgidos dentro de las propias órdenes religiosas, sobre todo la observancia franciscana, la labor del arzobispo de Toledo resultó un éxito casi completo en Castilla, aunque en los reinos orientales no ocurrió lo mismo. Allí, las religiosas, apoyadas por las oligarquías locales con las que mantenían lazos familiares directos, opusieron mayor resistencia a la implantación de la clausura, argumentando su estado de pobreza y los votos prometidos en su profesión, entre los que no solía figurar el encerramiento completo ${ }^{3}$.

La reforma del siglo XV favoreció el establecimiento de los decretos tridentinos setenta años después, ya que muchas comunidades venían realizando una vida religiosa conforme a unas normas escasamente diferenciadas de las conci-

\footnotetext{
1 Aunque en los paises católicos europeos también se persiguieron las formas alternativas de religiosidad femenina como las beguinas o los movimientos de vida activa que fueron conducidos finalmente hacia la clausura, lo cierto es que en Francia la mujer tuvo más posibilidades de desarrollar un modelo menos encerrado y, sobre todo, con mucha antelación respecto a la evolución española. Sobre los institutos de vida más activa y los intentos reformistas de mujeres como Luisa de Marillac, Mary Ward, Juana de Lestonnac o Juana de Chantal véase J. Álvarez GómEz, Historia de la Vida Religiosa, Vol. III, Madrid, 1990.

2 Hasta ahora los mejores estudios generales sobre este aspecto siguen siendo los de J. Garcla Oro, La reforma de los religiosos españoles en tiempos de los Reyes Católicos. Valladolid, 1969; Cisneros y la reforma del clero español, Madrid, 1973, y «La reforma de las órdenes religiosas en los siglos XV y XVI» en R. Garcia VILloslada (dir.), Historia de la Iglesia en España, Vol. III-1, Madrid, 1980 , pp. $211-350$.

${ }^{3}$ Los conflictos derivados de la reforma cisneriana en Cataluña fueron especialmente graves, concluyendo algunos con medidas drásticas, tales como la separación juridica de los frailes, las apelaciones a Roma e incluso el abandono del instituto religioso. Todo ello fue estudiado con gran precisión por T. DE AzconA, «Reforma de las cjarisas en Cataluña en tiempos de los Reyes Católicos» Collectanea Franciscana, 27 (1957), pp. 5-51 y «La reforma de las religiosas benedictinas y cistercienses en Catalufia en tiempos de los Reyes Católicos» Studia Monastica, 9 (1967), pp. 75-167.
}

Actas del I Congreso de Historia de la lglesia y el Mundo Hispánico Hispania Sacra, 52 (2000) 
liares. No obstante, la universalidad de Trento determinó que los institutos que no habían aceptado la acción de los Reyes Católicos hubieran de adaptarse obligatoriamente a los dictados de la Iglesia universal y al igual que en el siglo XV, la Monarquia, a través de Felipe II, va a apoyar directamente la reforma, auspiciada en muchos de sus puntos por el mismo monarca a través de sus enviados a las últimas sesiones del Concilio, precisamente aquéllas que abordaban los decretos disciplinarios del clero regular.

En la Sesión XXV los padres conciliares abordaron los cambios y el restablecimiento del primitivo espíritu de los institutos religiosos, para eliminar las costumbres relajadas, conminando a la ejecución exhaustiva de los votos monásticos, sobre todo la pobreza y la castidad, especificada en el precepto de clausura perpetua para las religiosas ${ }^{4}$. Se insistió mucho en la observancia de las diversas Reglas y en el estricto control que los superiores masculinos debian ejercer sobre las comunidades femeninas; en este sentido, el Capitulo V amenazaba a todos los obispos y otros superiores con la (maldición eterna) si no procuraban restablecer la clausura en los conventos donde se hubiera quebrantado y si no realizaban las visitas y reformas necesarias para refrenar a las monjas desobedientes, ayudándose de la autoridad civil si era necesario. Trento asienta así el eslogan ninguna monja fuera ningún seglar dentro, pero, además, toma medidas respecto a algunos de los motivos que implicaban el incumplimiento claustral. Así, ordena el traslado de los conventos en despoblado a las zonas urbanas, para evitar la inseguridad que dan estos entornos donde las entradas y salidas son mucho más accesibles, y hace especial hincapié en la cuestión económica, uno de los argumentos utilizados por las monjas para justificar sus salidas. Además, obliga a los claustros a admitir un número máximo de monjas en función de las rentas comunitarias y regula la administración básica de éstas, en especial el cobro adelantado de las dotes y la licencia otorgada a todas las órdenes para que puedan vivir de rentas y bienes en común, para evitar la pobreza y el endeudamiento que había conducido a disturbios, relajaciones y transgresión de la clausura ${ }^{5}$. Todos estos postulados habian de ser ejecutados por los superiores masculinos, imponiéndolos a las religiosas aunque tuvieran contenidos contrarios a la normativa que habían prometido en su profesión. De esta forma, el Concilio dio el definitivo aldabonazo al llamado «movimento femminile religioso» que habían encabezado mujeres como Santa Catalina de Siena en la Baja

\footnotetext{
${ }^{4}$ Hemos utilizado para nuestro estudio la edición espafiola de los decretos conciliares, editada en el siglo XVIII y conservada en la Biblioteca Nacional de Madrid: Sacrosanto y Ecuménico Concilio de Trento, 1545-1563, Madrid, 1735.

5 Incluso las ramas descalzas de clarisas y carmelitas y resto de órdenes podían acceder a las rentas comunitarias. Sólo una orden algo posterior, las capuchinas, se mantendrá on la más absoluta pobreza viviendo sólo de las limosnas y del trabajo de manos.
} 
Edad Media y otorgó a los hombres la potestad para realizar las reformas desde arriba, de las que sólo Santa Teresa será la excepción que confirme la regla ${ }^{6}$.

Así pues, clausura, dependencia de los prelados masculinos y control material y económico constituyen la base de la reforma tridentina, con lo que se ponen las bases para la disolución de los grandes monasterios femeninos de la Edad Media que desarrollaron su influencia política, social y religiosa casi al margen de sus homólogos masculinos. El predominio de los conventos inscritos en el marco urbano, casi todos ellos pertenecientes a las órdenes mendicantes (cuyas religiosas por tradición solían estar bajo el cuidado de los frailes), la función social y religiosa que se otorga a las monjas y la mentalidad barroca contribuirán a la transformación de la vida femenina en los claustros, tanto en la teoría como en la práctica.

Como era de esperar, numerosos conventos pusieron serias objeciones a la implantación de la clausura, ya fuera por motivos económicos y sociales, como religiosos ${ }^{7}$. Incluso en el centro de la Monarquía, en Madrid, se recogieron algunas quejas, como las del beaterio dominico de Santa Catalina de Siena, que se dedicaba al recogimiento temporal de mujeres laicas y cuidado de niñas como educandas. Durante los años 80 del siglo XVI son numerosos los testimonios de las religiosas sobre la precariedad de su situación, derivada de las transformaciones conciliares que las obligaban a vivir en clausura; en un memorial elevado al rey el 15 de diciembre de 1583 solicitan ayuda económica para trasladarse de lugar y construir una casa grande que consiguiera mantener separadas las habitaciones y estancias de religiosas y seglares:

«La priora y beatas y donzellas del monesterio dicen que su casa es de las mas necesarias de la Republica, mayormente en esta Corte y adonde habria de ser el mayor y mas copioso de toda Espafia y el mas favorecido, es mas pequefio y mas pobre que ninguno de los otros desta horden porque despues del Conçilio tridenttino esta prohibido que las mugeres seglares no puedan entrar ni vivir en los monesterios de monjas conbentuales y por no haber monesterio adonde poder estar rrecojidas mugeres ansi donzellas para casarse como viudas y casadas que por su rrecojimientto o por ausencia que hagan sus padres y maridos a negocios fuera desta Corte an suçedido muchas desgracias en que se a ofendido y de cada dia se debe de ofender mucho Nuestro Sefior con pecados publicos y secretos

${ }^{6}$ G. Duby y M. Perrot (dir.), Historia de las mujeres en Occidente, Vol. III, Madrid, 1992, pp. 175-178.

${ }^{7}$ El trabajo de M. J. ARANA, La clausura de las mujeres. Una lectura teológica de un praceso histórico, Bilbao, 1992 aborda el desartollo de la enclaustración impuesta por la jerarquía masculina a las religiosas y lo mismo ha hecho F. J. LoRENZo PNAR, Beatas y mancebas, Zamora, 1995, que centra su análisis en las resistencias de los beaterios y comunidades de terciarias a la imposición de la clausura y "Monjas disidentes. Las resistencias a la clausura en Zamora tras el Concilio de Trento" en A. MESTRE SANCHIS y E. GIMÉnEz LóPEZ, Disidencias y Exilios en la España Moderna. Actas de la IV Reunión Cientifica de la Asaciación Española de Historia Moderna, Vol. 2, Alicante, 1997, pp. 71-80.

Actas del I Congreso de Historia de la Iglesia y el Mundo Hispánico

Hispania Sacra, $52(2000)$ 


\begin{abstract}
por faltar donde estar trecojidas las mugeres... Y viendo esto quan necesario era al bien comun y servicio de Nuestro Sefior y que en la casa y monesterio donde estaban en la puerta de Valnadu no se podian recivir mugeres seglares mas de asta cantidad de una dozena dellas por no haber casa ni morada ni sitio competente para poderla hazer, y el mucho dafio que dello se siguia y las ynportunaciones que cada dia la dicha priora tenia y tiene para recivir seglares en el dicho monesterio y la falta de sitio del (...) $)^{\circ}$.
\end{abstract}

Entre los affos 70 del siglo XVI y la primera mitad del siglo XVII la mayor parte de los beaterios como Santa Catalina fueron desapareciendo, siendo obligados a transformase en conventos de clausura adscritos a las segundas órdenes de los diversos institutos ${ }^{9}$. El proceso trajo consigo la desaparición de la última oportunidad que le quedaba a la mujer de desarrollar una forma propia de religiosidad; por ello, desde mediados del siglo XVIl, los beaterios y las beatas constituyen una auténtica rareza, excepto las casas pertenecientes a las órdenes terceras, y adquirieron el significado peyorativo que ha durado hasta nuestros días, cuando no fueron perseguidas por su religiosidad heterodoxa ${ }^{10}$.

\title{
LA ADAPTACIÓN INSTITUCIONAL A TRENTO: LAS CONSTTTUCIONES
}

Tras la conclusión del Tridentino se hizo casi imprescindible la institucionalización en firme de los cambios introducidos, es decir, la redacción de unas Constituciones que incorporaran las novedades conciliares. Algunas de ellas no sufrieron muchos cambios, como ocurrió con los textos franciscanos, pero las normativas de órdenes más jóvenes, como las mercedarias, tuvieron bastantes variaciones.

Las Constituciones son normas globales de la vida religiosa que abarcan tres tipos básicos de contenidos: los jurídicos, los religiosos y los materiales. Entre los primeros se incluyen las cláusulas relacionadas con la jurisdicción a la que se han de someter las comunidades femeninas, a quiénes han de obedecer en los asuntos espirituales y materiales y de qué forma se han de ejecutar todos los actos de comunidad para que tengan validez legal. Los contenidos religiosos

\footnotetext{
${ }^{8}$ AGS, Cámara de Castilla, Leg. 558.

${ }^{9}$ Santa Catalina aceptó la clausura en 1620 , y lo mismo hizo a finales del reinado de Felipe IV el beaterio de las mercedarias fundadas por María de Mendoza, el famoso convento de las Góngoras. En Madrid sólo quedó abierto un beaterio, el de San José, ocupado por terciarias franciscanas y también fueron mujeres de la VOT regular las que se ocuparon de las casas de recogidas y arrepentidas madrilef́as.

10 De todo ello hablamos en C. SorJano Triguero, «Inquisicion, beatas y falsarios en el siglo XVII: Pautas del Santo Oficio para examinar visiones y apariciones» en A. MESTRE SANCHIS y E. GMitNEZ LÓPEZ, Disidencias y Exilios en la España Moderna Actas de la IV Reunión Cientifica de la Asociación Española de Historia Moderna, Vol. 2, Alicante, 1997, pp. 253-262.
} 
hacen referencia a los votos, cumplimiento de la regla, costumbres espirituales, oficio divino y demás aspectos relacionados con la vida contemplativa. Por último, denominamos materiales a las cláusulas que organizan la vida económica, la estructura de oficios, las condiciones exigidas para admitir novicias y otros aspectos que no afectan directamente al mundo espiritual. Es evidente que esta división no es estática, ya que lo temporal y lo espiritual, lo material y lo religioso se mezclan continuamente en el claustro.

Otro rasgo común a los textos constitucionales femeninos es su autor; son casi siempre los superiores masculinos quienes se encargan de redactar las normas, sin contar con la opinión de las religiosas en la mayor parte de los casos. En ellas se recoge la tradición del instituto y se incorporan las reformas desde arriba emanadas de Trento. La excepción a esta norma general la representa Teresa de Jesús, quien redactó personalmente la norma de vida carmelita descalza en 1568; no obstante, incluso este texto fue reformado con posterioridad por los definidores masculinos, quienes en algunos casos, como en los controvertidos temas de la limpieza de sangre y la elección libre de confesores, se separaron mucho del primitivo espíritu de Santa Teresa ${ }^{11}$.

Los textos que vamos a tratar con brevedad son los redactados e impresos en el siglo XVII y en su mayor parte perduraron durante el resto de la Edad Moderna como piedra básica de gobierno en las comunidades de clarisas, dominicas, mercedarias descalzas y carmelitas. Se trata de las Constituciones Generales para todas las monjas y religiosas sujetas a la obediencia de la Orden de Nuestro Padre San Francisco, aprobadas en el Capitulo General celebrado en Roma en 1639 y publicadas en Madrid en 1642; la Regla de Nuestro Padre San Agustín Doctor de la Iglesia y Constituciones o manual de las monjas del Orden de Santo Domingo de Guzmán, impresas en Madrid en 1656 y reimpresas en Sevilla en 1765; las Constituciones de las Religiosas Descalzas del Orden de Nuestra Señora de la Merced, impresas en 1683 y, por último, las ya mencionadas Constituciones carmelitas descalzas de 1568 , así como una norma particular la Regla y Constituciones de las religiosas carmelitas descalzas del convento de Nuestra Señora de la Natividad y San José, más conocido por el convento de la

11 Las Constituciones redactadas por la santa de Avila datan de 1568, pero el original no se conserva. En 1581, tras producirse la separación de descalzos y calzados, se aprobó un texto que recogia en esencia la espiritualidad de la descaicez teresiana, pero comenzaba a mermar la independencia y autoridad de las prioras. Por último, en 1592 se redactaron unas nuevas constituciones que colocaban para siempre a las monjas bajo la jurisdicción de los frailes carmelitas, sin que pudieran elegir otro tipo de confesores y guías espirituales. De esta forma, a fines del siglo XVI las carmelitas se adaptaron al espiritu tridentino a través đe las nomativas que les impusieron los frailes, alejándose de las aspiraciones de Santa Teresa. Para observar con detenimiento las diferencias entre el texto de la fundadora y la posterior legislación carmelita, VV. AA., El legado de Santa Teresa. Sus Constituciones, Madrid, 1981.

Actas del I Congreso de Historia de la Iglesia y el Mundo Hispánico

Hispania Sacra, 52 (2000) 
Baronesa, un convento de la orden calzada (a pesar del calificativo de las constituciones) que combina elementos de la descalcez, con una regla mitigada. El arzobispo de Toledo, Don Baltasar de Moscoso y Sandoval, bajo cuya jurisdicción se colocó la comunidad de La Baronesa, redactó las constituciones en $1662^{12}$. No vamos a entrar en los contenidos concretos de las normativas, ni en todos aquéllos que afectan a las costumbres religiosas y vida espiritual, sino que nos centraremos en los tres aspectos en los que más insistió Trento y que más van a transformar la estructura institucional: la clausura, el control exhaustivo de los superiores masculinos y la administración material de los conventos.

La importancia de la clausura en la Edad Moderna se halla estrechamente ligada al voto de castidad; si durante la Edad Media ambos términos no iban siempre unidos, desde el Concilio de Trento se convierten casi en una misma cuestión. Desde los breves de Pío V, la clausura de las monjas había de ser perpetua y sólo estaba permitido salir en caso de incendio, pestilencia, derrumbe del edificio o para fundar otros conventos o ser prelada en ofra comunidad, siempre con la licencia correspondiente del provincial masculino, so pena de excomunión mayor. Esta normativa es general para todos los institutos y se aconseja que cuando ocurran estas catástrofes, salgan todas las religiosas juntas, si es posible con licencia del superior o del vicario y acompantadas del capellán mayor o el confesor si se encuentran allí en ese momento. Como complemento al encerramiento, la clausura implica la prohibición tajante de entradas de eclesiásticos o laicos sin licencia, normativa recogida en todos los institutos ya desde sus propios orígenes.

Las Constituciones clarisas de 1639 imponen penas de privación de voz activa y pasiva y de oficio a la abadesa que consienta la entrada de seglares o eclesiásticos $\sin$ la licencia oportuna, recluyendo en la casa de disciplina a la religiosa que quebrantara el voto ${ }^{13}$. Entre las dominicas se permitía la entrada al monasterio de los reyes, el arzobispo y los patronos del convento, así como del general, provincial y visitador acompañados de frailes, pero pocas veces y conducidos por la priora y tres religiosas ancianas que son las únicas con las que podían hablar. Mientras hubiera alguien en el monasterio, debían ocultarse en sus celdas o reunirse en el coro, excepto las monjas legas, que permanecían en sus quehaceres, y se establecía pena de excomunión mayor ipso facto para cual-

12 Para evitar la reiteración de los títulos, las constituciones aparecerá citadas como C.F. (constituciones franciscanas), C.D. (constituciones dominicas), C.M. (constituciones mercedarias) y C.C.B. (constituciones del convento de la Baronesa).

[3 C.F. fol. 79v y ss. Un rigor especial se exige al sacristán del convento, a quien le está totalmente vedada la entrada en el mismo, aunque sea por causa urgente y del mismo modo, el confesor que entra en la enfermeria para administrar los sacramentos a las enfermas debe permanecer en el claustro el tiempo justo, so pena de privación de oficio para la abadesa durante tres affos. 
quier seglar o religioso que incumpliera esta norma ${ }^{14}$. Incluso una costumbre antigua, como era la entrada de mujeres seglares en el claustro para vivir como pisaderas temporales o definitivas, era vigilada de cerca por las disposiciones de las carmelitas recoletas: «Ninguna mujer seglar puede entrar en la clausura, aunque sea de cualquier estado y condición y si alguna acude con licencia de los prelados para ello, la priora suspenderá la ejecución hasta dar cuenta al prelado y obtener su orden también ${ }^{15}$.

La clausura no sólo debía ser interior, sino que tenía que demostrarse en público, lo que influyó en la arquitectura barroca conventual. Los edificios claustrales debían transformarse en auténticas fortalezas con muros altos, rejas, pinchos, celosías, velos negros y todo tipo de obstáculos que impidieran el trato demasiado familiar con seglares, la curiosidad del siglo y otras costumbres poco edificantes. Por ello, se regularon el tamaño y forma de los tornos, puertas reglares y demás estancias donde había relaciones con el exterior, como lo demuestra esta norma del convento de la Baronesa sobre su locutorio:

«(...) de hierro fuerte, con sus puas espesas, de tal manera, que por los claros della no han de poder entrar mas que tres dedos llanos. El marco de esta rexa ha de ser muy fuerte, y grueso, y por la parte de afuera se ha de poner una red de arambbre grueso, que este fixada, y clavada en el marco de mallas, tan menudas, que no quepa mas de un dedo, y ha de estar de modo, que apenas toque en las puas (...) Lo largo de esta rexa seran dos varas, y quarta, y lo alto en proporcion de arquitecturas, ${ }^{16}$.

Sin duda, el problema central en la observancia de la clausura eran los contactos con las personas del siglo, ya fueran laicas o eclesiásticas, producidos a través de las conversaciones en el locutorio, las confesiones y la correspondencia. Son los contactos personales los que pueden implicar desde una simple relajación, cuando son demasiado frecuentes, hasta un delito grave relacionado con la conducta sexual o moral de la religiosa y, por ello, todas las Constituciones limitan el número de visitas y las personas que pueden hablar con las monjas, siempre en presencia de las rederas o escuchas ${ }^{17}$. Las clarisas sólo podían

\footnotetext{
14 C.D., p. 95.

is C.C.B., pp. 129-130.

${ }^{16}$ C.C.B., pp. 126-128.

${ }^{17}$ Detrás de la nomativa sobre las conversaciones planea la sombra de uno de los quebraderos de cabeza de las autoridades masculinas: los devotos o galanes de monjas. La picaresca y la literatura airé́ mucho estos personajes durante el barroco, como lo recuerda J. DeLETTO Y PÑUELA, La vida religiosa espafiola bajo el cuarto Felipe, Madrid, 1963. En la práctica, los galanteos se mantuvieron hasta finales del XVII e incluso en el XVIII pero en conventos muy concretos y nunca constituyeron una agresión abierta contra la clausura, sino que se redujeron al intercambio de regalos y notas. Sobre la permanencia y naturaleza de esta prácticas de estas prácticas véase M. L. CANDAU CHACón, "Clérigos, monjas y fieles onubenses a finales del Barroco» en Huelva en su Historia 3, Huelva, 1989, pp. 283-
}

Actas del I Congreso de Historia de la Iglesia y el Mundo Hispánico Hispania Sacra, 52 (2000) 
recibir a parientes hasta segundo grado seis veces al anto ${ }^{18}$. La misma periodicidad se establecía entre las mercedarias con los familiares directos (padres, hermanos, abuelos), al igual que en el convento de la Baronesa, y aquéllas que no tenfan familia podían ser visitadas por quien las había criado o dotado para su profesión ${ }^{19}$. Sobre el papel y en teoría, eran las carmelitas recoletas las que poseian una mayor libertad a la hora de hablar con sus familiares, una diferencia respecto a los restantes claustros, motivada, quizá, por su adscripción a la jurisdicción episcopal. En sus constituciones se recoge que

«Todas las vezes que fuere preciso, y necessario que las Religiosas ayan de tratar algun negocio con persona de fuera de la casa se hara con licencia de la Priora, y con asistencia de la escucha, y en el Locutorio. Y si fuere padre, madre o hermanos, podra la Priora dispensar en que se levante el velo y con otras personas semejantes, a su disposicion» ${ }^{20}$.

En todos los casos, salvo urgencias repentinas, estaban prohibidas las visitas durante la noche y los actos de comunidad, así como durante Adviento, Cuaresma y Semana Santa, cuando también se limitaban al máximo las conversaciones con los frailes de la propia orden, excepto el visitador, los definidores y otros superiores y sólo para casos urgentes.

La segunda vía de contacto con el exterior era el confesionario. El sacramento de la penitencia es el ejercicio más privado que puede efectuar una religiosa, aunque en todos los institutos se recuerda la grave tentación que supone la frecuente confesión y conversación con los confesores y guías espirituales, en alusión, a veces directa y a veces indirecta, al delito de solicitación y a las relaciones ilícitas entre padre e hija espiritual ${ }^{21}$. Para evitar esta familiaridad,

302 y «Devociones y galanteos de monjas en Sevilla a finales del Antiguo Régimen» en I Congreso Internacional. El Monacato femenino en España, Portugal y América, León, 1992, Vol. II, pp. 551568.

is C.F., fol. 80r.

19 C.M., pp. 159 y ss. La visita no debía durar mucho tiempo, pero si la familia procedía de otra ciudad o lugar alejado podía extenderse durante todo el día, menos las horas de actos de comunidad. Incluso se preveía la posibilidad de que aquellos padres que visitaban a sus hijas muy de tarde en tarde podian hablar con ellas durante dos ó tres días, el mismo tiempo que podía charlar con persona espiritual y devota, aquella religiosa a la que nadie fuera a visitar nunca.

${ }^{20}$ C.C.B., pp. 326-327.

${ }^{21}$ Las obras sobre solicitación y relaciones ilicitas entre confesores y religiosas se han multiplicado en los últimos años, aunque el delito está más documentado entre lajcas y religiosos. Entre ellos debemos destacar las obras de A. SARRrón MORA, Sexualidad y confesión. La solicitación ante el Tribunal del Santo Oficio (siglos XVI-XIX), Madrid, 1994, y J. A. ALEJANDre, El veneno de Dios. La Inquisición de Sevilla ante el delito de solicitación en confesión, Madrid, 1994. Los tratadistas de la época insistieron en el tema con mucha frecuencia, en especial fray Antonio ARBIOL en sus muy 
los textos constitucionales regulaban la frecuencia del sacramento y la forma de ejecutarlo, mientras que en la práctica cotidiana el mejor medio de control era el cambio frecuente de los confesores, evitando que las religiosas se acostumbraran a la misma persona. En este sentido, la libertad de las monjas a la hora de elegir confesores se vio sustancialmente recortada, limitándola al momento de la muerte; incluso los confesores extraordinarios que debían nombrarse para obedecer las disposiciones tridentinas, eran designados por los superiores masculinos y procedían siempre de la misma orden, quedando prohibida la confesión con un fraile de otro instituto y mucho menos con un clérigo secular.

En este tipo de disposiciones se observa con claridad el control al que fueron sometidas las religiosas por sus prelados, quienes contaban con un mecanismo muy eficaz para desarrollar su labor, el voto de obediencia, considerado fundamental en todas las Constituciones:

«Por manera que como la Religion sea una escuela de virtudes, para alcanzar la perfeccion, es necessario, que las que en ella viven, sean guiadas, instruidas, y exercitadas por un Prelado, cuya voluntad sea como norte, a donde todas las Religiosas miren, negando su proprio querer... todos los discipulos se sujetan al Maestro; en la guerra, todos los Caballeros obedecen a un Capitán (...) Lo mismo vemos que los navegantes se sugetan, a lo que el ordena el Piloto, y no haciendolo se perderia el navio. Bien assi la Religion es un exercito muy ordenado, y cada dia, y hora damos batalla a los enemigos, carne, mundo, y satanas, los quales jamas duermenn ${ }^{22}$.

En última instancia, cualquier institución, sea eclesiástica o laica, está sujeta a una determinada jerarquía que la condiciona o controla desde fuera, pero la Iglesia Católica española proporciona el modelo más perfeccionado en el Antiguo Régimen ${ }^{23}$. En el caso de las religiosas, la presencia de los prelados es una constante vital y no sólo por las licencias, disposiciones y visitas, sino por la convivencia continua con figuras masculinas como los capellanes, vicarios y confesores que rigen el día a día de las religiosas. La incapacidad supuesta a las mujeres en el Antiguo Régimen para organizarse en institutos religiosos y participar activamente en su propio desarrollo, es casi un dogma asumido por las

conocidas Desengaños misticos a las almas detenidas o engañadas en el camino de la perfeccion. Zaragoza, 1706 y La religiosa instruida con doctrina de la Sagrada Escritura y Santos Padres de la Iglesia Católica. Para tadas las operaciones de su vida regular, desde que recibe el Habito Santo hasta la hora de su muerte. Zaragoza, 1717.

${ }^{22}$ C.D., p 222. El texto continúa aludiendo a los cánticos y a las cartas de San Pablo en las que se compara a la Iglesia con un poderoso ejército con armas de luz, la fe y los mandamientos, frente a la oscuridad del demonio.

${ }^{23}$ R. Fernández, La España Moderna. Siglo XVII, Vol. 4 del Manual de Historia de Espafia, Madrid, 1993, p. 636.

Actas del I Congreso de Historia de la Iglesia y el Mundo Hispánico Hispania Sacra, 52 (2000) 
mismas comunidades femeninas, bien adoctrinadas por sus superiores y por la literatura moral y religiosa de los siglos XVII y XVIII:

"Acerca de sus Prelados (la priora) debe ser muy obediente, guardando sus estatutos, y ordenaciones, y hacer y trabajar, que assi las guarden sus Religiosas, que si por ventura fueren muy rigurosas, y asperas, que trabaje con el Prelado que las modere, dando sus razones para con suavidad, y consuelo sirvan las Religiosas al Sefior; y si con todo esto el Prelado no las quisiere moderar, que procure animar a las Religiosas a la observancia de ellas, dandoles a entender, que aquello deber ser necessario, pues los Prelados lo mandan, dado que ellas no lo alcancens ${ }^{24}$.

Fray Antonio Arbiol, el padre Andrade y otros teóricos contribuyeron a la consolidación de una ideología perfectamente asumida por las monjas en los siglos modernos, quienes aceptaron su papel pasivo y dependiente; quizá por esta razón, el dinamismo y las religiosas contestatarias, visionarias y místicas del Barroco fueron desapareciendo y dieron paso en la llustración a unas mujeres de las que apenas nos ha quedado rastro ${ }^{25}$. Todas las disposiciones, excepto las que no tenían repercusión significativa en la vida religiosa, llevaban la aprobación de los prelados, el consejo de los vicarios que están cerca de las religiosas, la refrenda, en fin, de una autoridad a la que no se le debian discutir ni apelar sus decisiones:

«Declaramos, que, como consta por los Breves de Bonifacio IX y de Alejandro IV, todos los Monasterios de las Religiosas de Nuestra Orden estan encargados a los Reverendisimos Generales, y Priores Provinciales en cada provincia; y assi esta a su cargo, por si, o por otros religiosos de la dicha Orden, visitar, ordenar, poner y quitar todo, lo que quisieren, $y$ vieren, que conviene para el bien de la Religion, y observancia de los tales Monasterios» ${ }^{26}$.

Los prelados, como depositarios de la jurisdicción espiritual de las monjas, velaban por el cumplimiento de la regla, los votos y constituciones, las costum-

\footnotetext{
${ }^{24}$ C.D., p. 108.

${ }^{25}$ Las citadas obras de Arbiol o la del jesuíta A. de Andrade Libro de la guia de la virtud y de la imitación de Nuestra Señora. Madrid, 1642-1644 insistian en esa visión estática de la monja, tanto en su posición respecto a los prelados masculinos, como en las estructuras conventuales y en sus comportamientos religiosos, como acertadamente destacó J. Caro Baroja en su clásico Las formas complejas de la vida religiosa. Madrid, 1978. En el setecientos, la religiosa cede su puesto a la laica que encabeza la resistencia femenina en las relaciones de género. La importancia de la literatura religiosa en el siglo de las luces fue estudiada por A. GoNzALEZ NicOLAU, El mundo femenino en la mistica y los moralistas, Barcelona, 1970 y M. V. LOPEZ-CORDÓN, iLa literatura religiosa y moral como conformadora de la mentalidad femenina (1760-1860) n en VV. AA., La mujer en la Historia de España (siglos XVI-XX), Madrid, 1983, pp. 59-70.

${ }^{26}$ C.D., p.100. Este panorama institucional era el que dibujaban las Constituciones dominicas y es extensivo al resto de los institutos.
}

Actas del I Congreso de Historia de la Iglesia y el Mundo Hispánico

Hispania Sacra, 52 (2000) 
bres religiosas, celebraciones litúrgicas y demás cuestiones espirituales; por otro lado, la jurisdicción temporal implicaba el control sobre los oficios conventuales, el servicio prestado por el personal laico y eclesiástico, las recepciones de novicias, la adecuación de las religiosas a las rentas del convento, las dotes, las cargas que había de cumplir la comunidad (tanto económicas como espirituales, como eran las memorias de misas y capellanías) y, por supuesto, la supervisión completa de la hacienda y su administración. La licencia de los provinciales o del diocesano era necesaria para cualquier acto temporal del claustro, desde la imposición de un censo hasta la admisión de una novicia; pero el vicario encargado del cuidado espiritual ejercía de verdadero supervisor permanente, controlando a los criados, al mayordomo, las entradas y salidas de dinero del arca y cualquier anomalía que hubiera en el convento.

En esencia, estas funciones se hallaban presentes en el mismo origen de los diversos institutos femeninos, que nacieron al amparo de sus homólogos masculinos. No obstante, muchas ordenes se quejaron durante la Edad Media de la carga que suponía el cuidado de las monjas y Trento, al exigir a los obispos y a los definidores regulares la jurisdicción completa sobre las comunidades femeninas erradicó, al menos en teoría, los conflictos y perpetuó el papel secundario de las monjas.

La manera más antigua de controlar la vida religiosa femenina es la llamada visita o visitación, como aparece en la documentación. Este mecanismo es común a casi todas las instituciones del Antiguo Régimen, sean laicas o eclesiásticas, y su objetivo es vigilar la buena marcha del convento en todo su conjunto. Las visitas completas debían efectuarse cada año y medio, aunque en la mayor parte de los conventos este control atendía sólo a la hacienda, recibiendo la inspección de un procurador o contador propio de la orden. Cada tres años se ejecutaba una visita más completa, coincidiendo con la elección de oficios, a la que acudía el eclesiástico correspondiente con el fin de presidir las elecciones y repasar el estado del convento. Por último, existen las llamadas visitas extraordinarias, surgidas por motivos especiales, casi siempre relacionados con alteraciones dentro de los claustros o con la ejecución de procesos de reforma general de la orden, como ocurrió durante los siguientes afios a la promulgación de los decretos tridentinos o durante el periodo reformista del Cardenal Cisneros. Desde el punto de vista teórico, el mecanismo no variaba en exceso. Hemos tomado como ejemplo el modelo del convento de la Baronesa, donde el arzobispo de Toledo debía nombrar un visitador que acudiera al claustro dos veces en cada trienio, coincidiendo una de las fechas con la elección de oficios:

«El Visitador ha de tener especial comunion del Prelado, y quando sea tiempo ordenara a la Superiora, que junte la Comunidad en el Coro, y alli el dicho visitador las hara notorio como quiere visitar el Convento... entonara la Antifona acostumbrada con su ora-

Actas del I Congreso de Historia de la Iglesia y el Mundo Hispánico Hispania Sacra, $52(2000)$ 
cion; y si pareciere conveniente, hará una platica, exortando a las Religiosas el cumplimiento de sus obligaciones, observancia de su Regla y lo demas que le dictare su espiritu, y las dara a entender el tiempo en que ha de empeçar la visita secreta; (...) es necessario que todas las Religiosas (...) vayan premeditando, y advirtiendo las faltas, y cosas que tuvieren reconocido ser algo dignas de enmienda, ansi en comun, como en particular, en cada uno de los sugetos del dicho Convento... que lo deven hazer por el servicio de Dios, y conveniencia espiritual, y temporal de el dicho Convento, y sugetos de él, sin moverse por afecto, 0 intereses humanos, assegurandolas que seran oidas, y se las guardara secreto con fidelidad; y entonces podra el Visitador pedir la Regla, y Constituciones de dicho Convento, las Visitas antecedentes, $y$ una memoria que contenga los nombres de tadas las Religiosas, y demas papeles que le parecieren necessarios (...) el dia sefialado podra dezir Missa el Visitador (...) y en ella visitara el Sagrario, donde esta el Santissimo Sacramento, y el Santo Olio, Altares y adorno de la Iglesia; y despues llamara por el locutorio, o lugar destinado a cada una de las Religiosas por su antiguedad, o como mejor le pareciere, y las oira lo que quisieren dezir, y las ira preguntando en la forma siguiente.

Si en el dicho Convento se guarda nuestra Sagrada Ley, sus santos Mandamientos, y los de la Santa Madre Iglesia, los quatro Votos, las Reglas y Constituciones, y loables costumbres de esta Religion, y Convento y los mandamientos del Prelado, y de las Visitas antecedentes (...) Si acuden las Religiosas en comun, o en particular al Coro, Oficios Divinos, oracion, y los demas actos de Comunidad a los tiempos, y horas seffalados. Si se guarda la compostura necessaria en los vestidos, tratos, conversaciones, y silencio y todo lo demas que mira a la obediencia regular. Si cada una acude a su ministerio con puntualidad, y se socorre con caridad a las necessidades de las Religiosas... con especial cuidado de las enfermas. Si se cumple con la obligacion de Missas, y sufragios por vivos, y difuntos, que dicho Convento tiene de cargo (...) y las Missas por las Religiosas Difuntas. Si se guarda la clausura con puntualidad que pide el estado, y profession; y el Visitador puede afiadir todo lo que juzgare sea de importancia (...).

(Si le parece necesario) podra entrar en la clausura para examinar toda la casa y si salen culpadas algunas Religiosas las podra corregir y penitenciar a solas o en presencia de la Comunidad, segun la calidad de la culpa.

(Luego visitará) los libros del dicho Convento, y tomara la quenta a los Administradores, Mayordomos, y demas personas a cuyo cargo este darlas, para que conste con toda claridad y distincion de recibo, y gasto, cerrandoles en forma, y modo que se pueda executans $^{27}$.

Los poderes del visitador eran plenos, pudiendo imponer penitencias y castigos a las religiosas, deponer oficios de dentro y fuera de la clausura si lo consideraba oportuno y señalar las líneas que debia seguir la administración económica. Características similares poseían los demás institutos, donde los visitadores dominicos, mercedarios y franciscanos, nombrados por el provincial y acompañados del procurador o contador de la provincia, atendían a las cuestiones religiosas y temporales ${ }^{28}$.

${ }^{27}$ C.C.B., pp. 253-265.

${ }^{28}$ El mecanismo de la visita ordinaria y extraordinaria en la orden franciscana fue analizado por $E$. MARTiNez Runz, «La visita en los conventos clarianos de la Ilustración. El convento de Santa Isabel de 
Por último, el Concilio de Trento fomentó el cambio económico que iban a experimentar las comunidades femeninas en la Edad Moderna. Los padres conciliares insistieron en un hecho: el saneamiento de la hacienda, una reforma necesaria para evitar la mendicidad e incumplir con ella la clausura. La adecuación del número de religiosas a las rentas habia constituído uno de los puntos básicos de la reforma Cisneriana y después del Concilio los institutos religiosos reformaron sus estructuras. Serán de nuevo los superiores quienes establezcan el número máximo de monjas que puede albergar cada claustro y también quienes dicten las normas básicas de la administración económica. Como el objetivo de los conventos es perpetuarse en el tiempo, los prelados instan a las monjas a invertir en rentas perpetuas y seguras, es decir, censos y juros. De esta forma, la antigua vitalidad económica de los monasterios medievales da paso a las economías rentistas urbanas que caracterizaron los siglos modernos.

Las monjas tuvieron bastante atadas las manos en la administración de su hacienda; las clarisas contaban con un mayordomo secular controlado por el vicario del convento; en el caso de las dominicas, la injerencia de los frailes era aún mayor, ya que el procurador del convento era el propio vicario, tal y como se desprende de las escrituras de nombramiento del oficio en el convento madrileño de Santa Catalina de Siena y en los claustros dominicanos de Zamora y Caleruega ${ }^{29}$. Las mercedarias depositaron su administración en mayordomos laicos, pero en época de crisis y con objeto de eliminar gastos salariales, la presencia de los frailes aumentaba, al hacerse cargo del cobro y administración de las rentas femeninas, como hicieron las religiosas del convento madrileño de las Góngoras a finales del siglo XVII ${ }^{30}$. Por último, las carmelitas descalzas contaban con un mayordomo secular para el cobro de las rentas, pero era la Procuraduría General de la Orden quien controlaba el grueso de su economía.

En las Constituciones dominicas se recuerda que la intervención de los prelados de la orden era obligatoria «para que con su parecer, la hacienda se mejore», siendo castigada la priora que tomara cualquier decisión sin la licencia de sus superiores, a los que debía obediencia ${ }^{31}$. Las líneas directrices en la inver-

\footnotetext{
Valladolid» en Actas del Congreso Internacional. Las clarisas en España y Portugal, Actas II, Vol. I, Madrid, 1994, pp. 391-406, en el que además de exponer su estructura, insiste en las cuestiones más sigo nificativas: los votos, la Regla, la clausura, oficio divino y hacienda comunitaria. También en este mismo volumen, M. P. PI CorRales, «La provincia de Santiago. Visiones criticas de la vida conventual en las comunidades de clarisas (1699-1741)", pp. 371-390, nos acerca a los libros de patente surgidos tras las visitas, en los que se recogen los aspectos que habían de ser reformados en las comunidades de clarisas.

29 F. ZURDo, Zamora dominicana. Zamora, 1994, y C. GonZÁleZ, Real Monasterio de Santo Domingo de Caleruega, Salamanca, 1993.

${ }^{30}$ A.H.N., Consejos, Leg. 16.253.

${ }^{31}$ C.D., p. 110.
}

Actas del I Congreso de Historia de la Iglesia y el Mundo Hispánico Hispania Sacra, 52 (2000) 
sión, la cuantía máxima de la dote, la tasación y estimación de los gastos y otros contenidos fundamentales del estado material de los claustros femeninos se hallaba controlado por los respectivos prelados y la influencia de éstos aumentó conforme avanzamos en la Edad Moderna.

Así pues, clausura y supeditación a la autoridad masculina fueron las normas básicas que contribuyeron a transformar en mayor medida los claustros femeninos en la Edad Moderna. La consolidación del papel pasivo de la mujer en la iglesia y la sociedad espaniola en su conjunto ${ }^{32}$ condujo, sobre todo en el Barroco, al desarrollo del único medio de "escape» ante los cambios que se habían producido, de lo que se deriva la gran abundancia de visionarias, pseudomísticas y milagreras por toda la geografía española del siglo XVII ${ }^{33}$. En la siguiente centuria, una vez atenuadas y controladas las formas de religiosidad barroca, la vida de las religiosas parece diluirse en la montonia, e incluso en una época tan hostil y cambiante para los regulares como el reinado de Carlos III, apenas contamos con noticias de mujeres. sobresalientes y actividad espiritual de altura en los claustros ${ }^{34}$. Al final, Trento y las normativas particulares de cada instituto dieron sus frutos y habrá que esperar al siglo XIX para empezar a ver un nuevo momento de esplendor en el desarrollo de las formas de religiosidad femenina, esta vez sí, vinculadas a la vida activa.

32 Recordemos que los primeros institutos de ensefianza no se implantan hasta el siglo XVIII a través de las Salesas, que, por supuesto respetan la clausura, y que las Hijas de la Caridad no llegan a Espafia hasta el reinado de Carlos IV.

${ }^{33}$ Las formas femeninas de piedad en el Barroco fueron espléndidamente estudiadas en una obra ya clásiça de J. L. SANCHEZ LoRA, Mujeres, conventos y formas de religiosidad barroca, Madrid, 1988.

${ }^{34}$ Entre los muchos estudios sobre las reformas de Carlos III y sus ministros, en especial Campomanes y Aranda, respecto a las b́rdenes religiosas, en especial las mendicantes, sigue siendo obligatorio el trabajo de A. L. CoRTEs PENA, La politica religiosa de Carlos III y las órdenes mendicantes, Granada, 1989 y hemos de destacar también el de C. CARo LópEZ, «La reducción de las ordenes regulares: Documentos para un caso de la política religiosa en tiempos de Carlos IIIn, Hispania Sacra LXIV (1992), pp. 335-392, y el de J. Izquierdo MARTti (et. al.), «La reforma de los regulares durante el reinado de Carlos III. Una valoración a través del ejemplo madrilefion, en Carlos III, Madrid y la llustración. Contradicciones de un proyecto reformista, Madrid, 1988, pp. 189-222, centrados en el caso madrileîto. 